\title{
Determining the Pension Benefit Obligation of a Defined Benefit Plan: Applying a Multivariate ARIMA Stochastic Model
}

\author{
Jeffrey Tim Query ${ }^{1}(\mathbb{D})$, Evaristo Diz $^{2}$ \\ ${ }^{1}$ Professor, Department of Finance, New Mexico State University, USA. \\ ${ }^{2}$ Academic Director, Universidad Católica Andrés Bello, Bolivarian Republic of Venezuela \& \\ President EDiz Actuarial Services and Consulting.
}

Type of Work: Peer Reviewed.

DOl: https://dx.doi.org/10.21013/jmss.v17.n4.p5

\section{How to cite this paper:}

Query, J. T., Diz., E. (2021). Determining the Pension Benefit Obligation of a Defined Benefit Plan: Applying a Multivariate ARIMA Stochastic Model. IRA-International Journal of Management \& Social Sciences (ISSN 2455-2267), 17(4), 145-159. DOl: https://dx.doi.org/10.21013/jmss.v17.n4.p5

\section{(c) IRA Academico Research.}

This full-text of this paper is available under Open Access subject to a Creative Commons Attribution-NonCommercial 4.0 International License $\square$ and further subject to a proper citation of its primary publication source.

Disclaimer: The scholarly papers as reviewed and published by IRA Academico Research are the views and opinions of their respective authors and are not the views or opinions of IRA Academico Research. IRA Academico Research disclaims any harm or loss caused due to the published content to any party.

IRA Academico Research is an institutional publisher member of Publishers International Linking Association Inc. (PILA-CrossRef), USA. Being an institutional signatory to the Budapest Open Access Initiative, Hungary, the content published by IRA Academico Research is available under Open Access. IRA Academico Research is also a registered content provider under Open Access Initiative Protocol for Metadata Harvesting (OAI-PMH).

This paper is peer-reviewed following IRA Academico Research's Peer Review Program $[7$.

Jeffrey Tim Query (D)/ 


\section{ABSTRACT}

In this study, we examine the robustness of fit for a multivariate and an autoregressive integrated moving average model to a data sample time series type. The sample is a recurrent actuarial data set for a 10-year horizon. We utilize this methodology to contrast with stochastic models to make projections beyond the data horizon. Our key results suggest that both types of models are useful for making predictions of actuarial liability levels given by PBO Projected Benefit Obligations on and off the horizon of the sample time series. As we have seen in prior research, the use of multivariate models for control and auditing purposes is widely recommended. Fast and reliable statistical estimates are desirable in all cases, whether for audit purposes or to verify and validate miscellaneous actuarial results.

Keywords: Multivariate Regression, ARIMA Model, Regressive Model, Pensions.

\section{Introduction and Objective}

In this study, we analyze the goodness of fit using a multivariate regression model and a self-regressive autoregressive integrated moving average (ARIMA)-type regression model to our data sample, which is basically recurrent valuations from the analytical point of view for a 10-year horizon. Those results are then contrasted with the results of a regression model for series data within the sample ultimately, and another ARIMA to make projections beyond the data horizon. By using lagged moving averages to smooth time series data, autoregressive integrated moving average (ARIMA) models are used to predict future values based on past values. In other words, autoregressive models implicitly assume that the future will resemble the past. In theory, ARIMA models are the most general class of models for forecasting a time series which can be made to be "stationary" via such tools as differencing, or nonlinear transformations such as logging or deflating. If a time series random variable has statistical properties that are all constant over time, it is stationary. Characteristics of a stationary series include having no trend, short-term random time patterns always looking the same in a statistical sense, and variations around its mean having a constant amplitude. An ARIMA model can be described as a filter used to separate the signal from the noise.

In a 2018 study by Diz and Query, a multivariate regression model is determined that allows computation of the actuarial liability of social benefits using a group of potential predictors. In general, the previous or independent predictors are the same as those utilized in an actuarial valuation of labor commitments. Several linear and nonlinear models are considered and tested in this study. Among the most important findings of this research is that the PBO or Actuarial Liability depends fundamentally on a linear basis of two fundamental variables in the quantification of Social Benefits -the Guarantees and the Social Benefits to Pay (PSP).

\section{Motivation for Study}

In actuarial practice, the need to make estimates of the level of liabilities within and outside a time horizon is very common given a series of sample observations derived from the realization of recurrent actuarial assessments. In this paper, two stochastic models are developed; to make predictions within the horizon of the sample time series and projections outside it. Predictions within the sample domain use a multivariate regression model based on one or more predictor variables of the best possible fit. Outside the domain, an ARIMA-type self-regulating stochastic model was adjusted to model liabilities levels for five future years.

\section{Methodology Use for Determining Actuarial Liability}

Description of actuarial model variables:

3.1 Warranty: Amount of Social Benefits type defined benefit plans applicable in Venezuelan labor law.

$$
G=\sum S_{t} z_{t}
$$

$S_{t}:$ Salary at time $t$

$z_{t}:$ Profit rate applicable at time $t$

3.2 Retroactive Benefits: This benefit is exponential in nature, and the amount is calculated by collecting all the services accumulated to date by the respective salary.

$$
R_{t}=S_{t} t
$$


$S_{t}:$ Salary

t: years of accumulated service

3.3 Differential Benefits: Represents the difference in Benefits between retroactive accounting and warranty.

$D_{-}(t=)$ Earnings spread

$$
D_{t=} R_{t}-G_{t}
$$

3.4 Service: Seniority in the company

$x$ : Actual Age

$$
x-y
$$

y: Entry Age

3.5 Lottt Service: Recognizable or creditable service for retroactivity purposes.

$$
\begin{gathered}
\text { Serv }-\Delta \\
\Delta: \text { Restricciones }
\end{gathered}
$$

LOTTT refers to the Organic labor law in Venezuela. LOTTT SERVICES means accredited service (Seniority) under LOTTT for retroactivity calculation.

3.6 Differential Benefit: The maximum positive difference between retroactivity and warranty.

$$
B_{t}=\operatorname{MAX}\left(R_{t}-G_{t}, 0\right)
$$

\subsection{Actuarial Liabilities (Unit Projected Benefit):}

$P B O_{t}=B_{t} A_{t}$

$A_{t}:$ Expected present value of the unit benefit payment

$A_{t}=f\left(i, \Delta, t p_{x} q_{x}\right)$

$i$ : Interest rate

s: Rate of salary increase

$t p_{x} q_{x}$ : Probability of Unit Payment

\section{Demographic and Salary Descriptions of the Sample}

4.1 The zero-year sample is described below.

\begin{tabular}{|l|r|}
\hline SAMPLE & $\mathbf{3 0 / 0 6 / 2 0 2 0}$ \\
\hline POPULATION & $\mathbf{1 3 4 . 0 0}$ \\
CURRENT AGE (AVERAGE) & 41.69 \\
CURRENT SERVICE (AVERAGE) & 11.32 \\
INTEGRAL SALARY (AVERAGE) & 68.515 .703 .36 \\
PAYROLLMONTH & 9.181 .104 .250 .64 \\
WARRANTY PS & 5.259 .029 .228 .22 \\
RETROACTIVE PS & 107.523 .454 .040 .37 \\
PS TO PAY & 107.523 .454 .040 .37 \\
DIF TO PAY VS GUARANTEES & 102.264 .424 .812 .15 \\
\hline
\end{tabular}


IRA-International Journal of Management \& Social Sciences

4.2 Actuarial valuations were made under the Projected Benefit Credit Unit Method. In general, actuarial obligations and annual service costs are modeled (PBO and CS) over the age of 10.

\begin{tabular}{|l|r|r|}
\hline & \multicolumn{1}{|c|}{ PBO } & \multicolumn{1}{c|}{ CS } \\
\hline YEAR 0 & 599.581 .716 .879 .925 & 158.390 .553 .792 .612 \\
YEAR 1 & 218.504 .785 .809 .353 & 372.689 .113 .444 .659 \\
YEAR 3 & 7.164 .245 .675 .695 & 914.233 .917 .423 .892 \\
YEAR 3 & 193.410 .357 .839 .552 & 183.989 .742 .883 .175 \\
YEAR 4 & 415.185 .126 .949 .638 & 367.284 .435 .386 .488 \\
YEAR 5 & 798.854 .276 .562 .709 & 594.322 .070 .312 .557 \\
YEAR 6 & 127.672 .317 .372 .548 & 723.696 .004 .939 .019 \\
YEAR 7 & 176264597955.79 & 777.578 .845 .397 .996 \\
YEAR 8 & 214.968 .888 .852 .038 & 814.681 .692 .195 .149 \\
YEAR 9 & 249.996 .814 .127 .197 & 810.811 .800 .383 .123 \\
YEAR 10 & 284980458379.68 & 794.778 .715 .261 .004 \\
\hline
\end{tabular}

From the valuation results of the initial year, the 10 successive actuarial valuations are developed and the following descriptive statistics of future years are found.

\begin{tabular}{|l|r|r|r|r|}
\cline { 2 - 5 } \multicolumn{1}{c|}{} & \multicolumn{4}{|c|}{ TOTALS } \\
\cline { 2 - 5 } \multicolumn{1}{c|}{} & \multicolumn{1}{|c|}{ TOTAL } & \multicolumn{1}{c|}{ MIN } & \multicolumn{1}{c|}{ MAX } & \multicolumn{1}{c|}{ DESV. TIP } \\
\cline { 2 - 5 } & 80343950061.91 & 26847120.56 & 7927232001.51 & 756.769 .421 .733 .148 \\
\hline YEAR 0 & 292.796 .412 .984 .533 & 318.216 .369 .781 .985 & 273.839 .681 .788 .948 & 257.550 .745 .029 .459 \\
YEAR 1 & 960008920543.13 & 151.923 .449 .559 .289 & 874.143 .417 .932 .705 & 81.170 .088 .298 .588 \\
YEAR 3 & 2.591 .698 .795 .050 & 480.944 .269 .931 .031 & 231.628 .064 .673 .957 & 212.777 .804 .880 .476 \\
YEAR3 & 5563480701125.15 & 111.587 .464 .495 .244 & 489.993 .791 .402 .217 & 445.988 .391 .154 .724 \\
YEAR 4 & 10704647305940.3 & 227.906 .257 .701 .688 & 931.522 .560 .022 .985 & 841.278 .635 .020 .668 \\
YEAR 5 & 17108090527921.4 & 381.700 .496 .344 .534 & 1473919782921.89 & 132.197 .346 .899 .611 \\
YEAR 6 & 23619456126075.8 & 547.320 .011 .543 .991 & 2019035244005.26 & 179.965 .244 .993 .454 \\
YEAR 7 & 28805831106173.1 & 687.620 .480 .392 .791 & 2444409060434.9 & 216.824 .770 .843 .672 \\
YEAR 8 & 33499573093044.4 & 820.001 .298 .440 .968 & 2828611902071.11 & 249.655 .073 .896 .059 \\
YEAR 9 & 38187381422877.1 & 954.091 .067 .078 .157 & 3211797561920.43 & 282.227 .235 .423 .713 \\
\hline YEAR 10 & & \multicolumn{3}{|c|}{}
\end{tabular}

\section{Formulation of Statistical Models}

Two models are adjusted from the results, and are described in this section:

\subsection{Multivariate Regression Model for predictions within the domain (10 years).}

There is Little extant research about this particular subject and this is one of the reasons for our investigation. Most of the principal auditing companies worldwide engage statisticians using multivariate regression analysis in order to check the actuarial valuations and results. The methodology is less expensive, quicker, and in terms of order of magnitude, the figures are basically the same. These statistical models allow us to contrast results based on evidence.

\section{MULTIPLE REGRESSION - PBO}

Dependent variable: pbo Independent variables:

service (serv)

tint $(229 \%)$ 
NOTE: Tint means rate of interest; in Spanish it is tasa de interés, in short, "tint"

\subsection{Multiple Regression Statistics}

\begin{tabular}{|l|l|l|l|l|}
\hline & & Standard & Statistical & \\
\hline Parameter & Estimate & Error & $\boldsymbol{T}$ & P-value \\
\hline constant & $-1.15976 \mathrm{E} 14$ & $1.34678 \mathrm{E} 13$ & -8.61138 & 0.0001 \\
\hline service & $7.3446 \mathrm{E} 12$ & $7.02078 \mathrm{E} 11$ & 10.4612 & 0.0000 \\
\hline tint & $1.31754 \mathrm{E} 13$ & $2.65369 \mathrm{E} 12$ & 4.96494 & 0.0016 \\
\hline
\end{tabular}

\subsection{Variance Analysis}

\begin{tabular}{|l|l|l|l|l|l|}
\hline fountain & Sum of Squares & Gl & Medium Square & F-Reason & $P$-value \\
\hline model & $1.41345 \mathrm{E} 27$ & 2 & $7.06724 \mathrm{E} 26$ & 206.78 & $\mathbf{0 . 0 0 0 0}$ \\
\hline residue & $2.39243 \mathrm{E} 25$ & 7 & $3.41776 \mathrm{E} 24$ & & \\
\hline Total (Corr.) & $1.43737 \mathrm{E} 27$ & 9 & & & \\
\hline
\end{tabular}

R-square-98.3356 percent

R-square (adjusted for g.1.) - 97.86 percent

Standard est error. 1 .84872E12

Average Absolute Error - 1,34777E12

Durbin-Watson Statistician s 1,38844 (Ps 0,0190)

Delayed waste autocorrelation $1 \times 0.111525$

The output shows the results of adjusting a multiple linear regression model to describe the relationship between pbo and 2 independent variables. The equation of the fitted model is:

$$
\text { pbo }=1.15976 \mathrm{E} 14+7.3446 \mathrm{E} 12 * \text { service }+1.31754 \mathrm{E} 13 * \text { tint }
$$

Since the P-value in the ANOVA table is less than 0.05, there is a statistically significant relationship between variables with a $95.0 \%$ confidence level. The R-Square statistic indicates that the model thus adjusted explains 98.34\% of the variability in pbo. The adjusted R-Square statistic, which is more appropriate for comparing models with a different number of independent variables, is $97.86 \%$. The standard estimated error shows that the standard deviation of the residuals is $1.84872 \mathrm{E} 12$. This value can be used to construct boundaries for new observations by selecting the Reports option from the text menu. The average absolute error (MAE) of $1.34777 \mathrm{E} 12$ is the average value of the residuals. The Durbin-Watson (DW) statistic examines the residuals to determine if there are any significant correlations based on the order in which they are presented in the data file. Since the P-value is less than 0.05 , there is an indication of a possible serial correlation with a $95.0 \%$ confidence level. Plot the residuals versus the row number to see if there are any patterns that can be detected.

To determine whether the model can be simplified, notice that the highest P-value of the independent variables is 0.0016 , which corresponds to tint. Since the P-value is less than 0.05 , that term is statistically significant with a confidence level of $95.0 \%$. Consequently, you probably wouldn't want to remove any variables from the model. 
PBO RESIDUE COMPONENT GRAPH

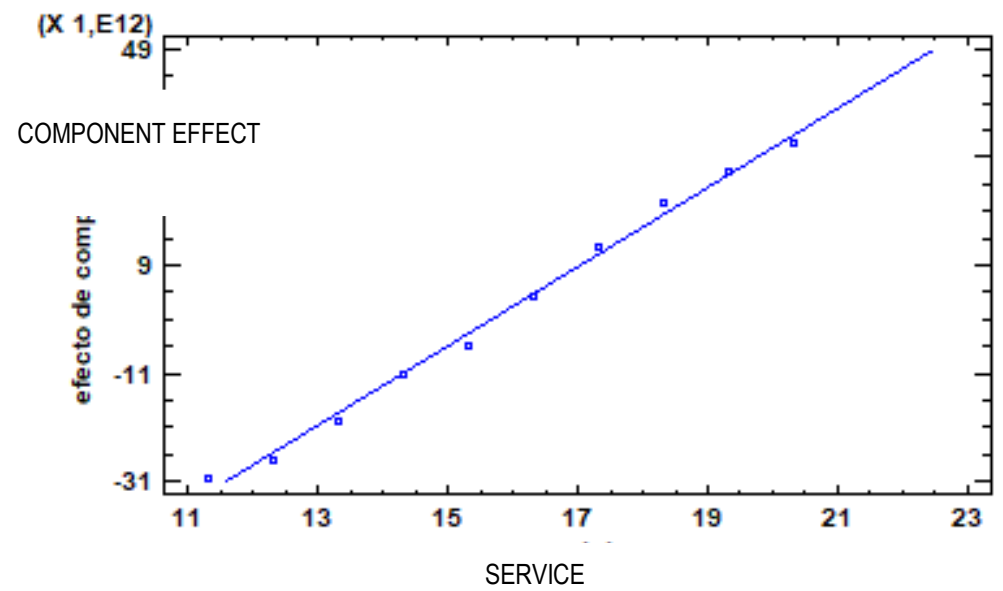

Additional ANOVA for Variables in Adjusted Order

\begin{tabular}{|l|l|l|l|l|l|}
\hline Fountain & Sum of squares & Gl & Mean Square & F-Ratio & P-Value \\
\hline $\begin{array}{l}\text { Years of } \\
\text { service }\end{array}$ & $1.3292 \mathrm{E} 27$ & 1 & $1.3292 \mathrm{E} 27$ & 388.91 & 0.0000 \\
\hline Tint & $8.42497 \mathrm{E} 25$ & 1 & $8.42497 \mathrm{E} 25$ & 24.65 & 0.0016 \\
\hline Model & $1.41345 \mathrm{E} 27$ & 2 & & & \\
\hline
\end{tabular}

This table shows the statistical significance of each variable as it was added to the model. You can use this table to help you determine if the model can be simplified, especially if you are fitting a polynomial.

PBO CHART

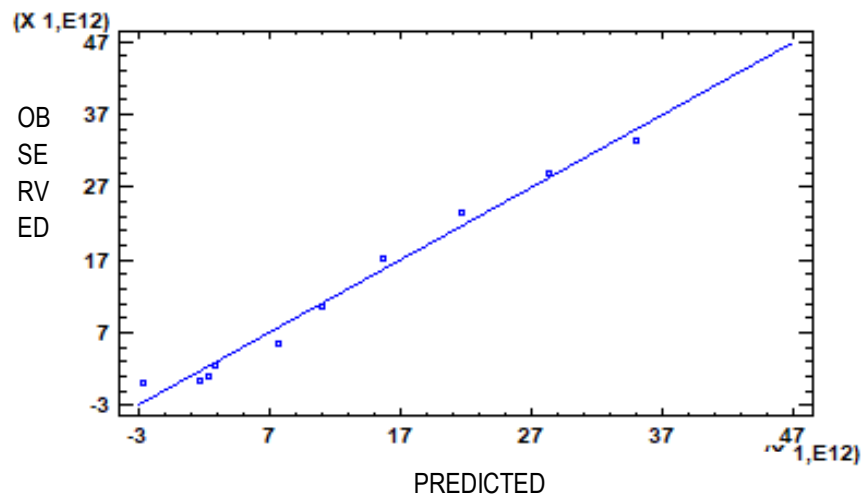

95.0\% CONFIDENCE INTERVALS FOR COEFFICIENT ESTIMATES

\begin{tabular}{|l|l|l|l|l|}
\hline & & Standard & & \\
\hline Parameter & Estimate & error & Lower limit & Upper limit \\
\hline Constant & $-1.15976 \mathrm{E} 14$ & $1.34678 \mathrm{E} 13$ & $-1.47822 \mathrm{E} 14$ & $-8.41297 \mathrm{E} 13$ \\
\hline Yearsofservice & $7.3446 \mathrm{E} 12$ & $7.02078 \mathrm{E} 11$ & $5.68445 \mathrm{E} 12$ & $9.00476 \mathrm{E} 12$ \\
\hline tint & $1.31754 \mathrm{E} 13$ & $2.65369 \mathrm{E} 12$ & $6.9004 \mathrm{E} 12$ & $1.94504 \mathrm{E} 13$ \\
\hline
\end{tabular}


This table shows $95.0 \%$ confidence intervals for the coefficients in the model. Confidence intervals show how accurately the coefficients can be estimated given the amount of data available, and the level of noise that is present.

RESIDUAL CHART

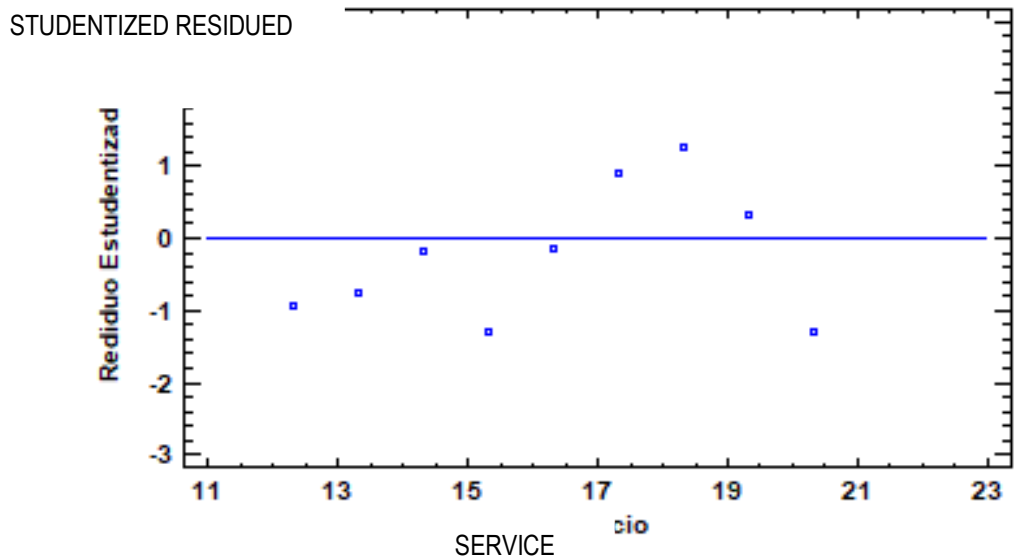

Correlation matrix for coefficient estimates

\begin{tabular}{|l|l|l|l|}
\hline & Constant & Service & tint \\
\hline Constant & 1.0000 & -0.9977 & -0.9701 \\
\hline Years of service & -0.9977 & 1.0000 & 0.9572 \\
\hline tint & -0.9701 & 0.9572 & 1.0000 \\
\hline
\end{tabular}

This table shows the estimated correlations between the coefficients in the fitted model. These correlations can be used to detect the presence of severe multicollinearity, that is, a correlation between the predictor variables. In this case, there is 1 correlation with an absolute value greater than 0.5 (not including the constant term).

RESIDUAL CHART

\section{STUDENTIZED RESIDUED}

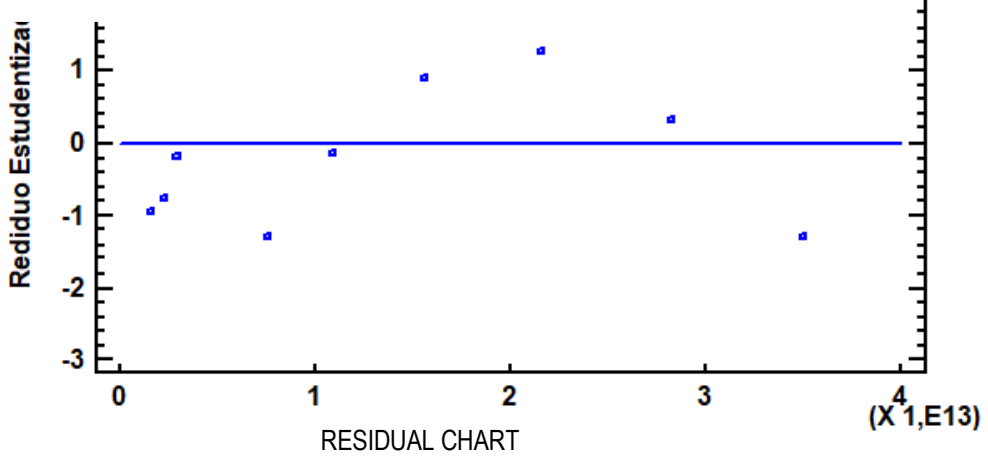


PBO Regression Results

\begin{tabular}{|l|l|l|l|l|l|}
\hline & Tight & Error Est. & Bottom 95.0\% & Top 95.0\% & Bottom 95.0\% \\
\hline Row & LC for Forecast & LC for Forecast & LC for Forecast & LC for the Average \\
\hline
\end{tabular}

\begin{tabular}{|l|l|}
\hline & Top $95.0 \%$ \\
\hline row & LC for the Average \\
\hline
\end{tabular}

This table contains information about pbo which was generated using the fitted model. The table includes:

(1) the predicted pbo values using the fitted model

(2) the standard error to reach the predicted value

(3) $95.0 \%$ forecast intervals for new observations

(4) $95.0 \%$ confidence intervals for the mean response

RESIDUAL CHART

\section{STUDENTIZED RESIDUED}

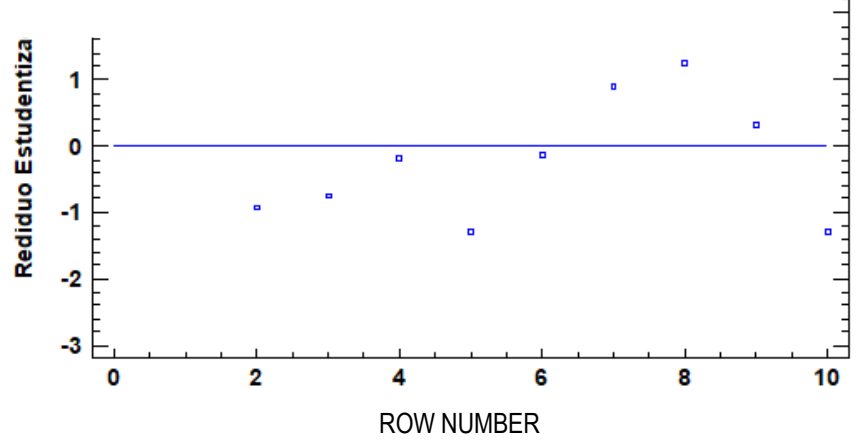

Atypical Data (Waste)

\begin{tabular}{|l|l|l|l|l|}
\hline & & & & Residual \\
\hline Row & $Y$ & Predicted $Y$ & Residual & Studentized \\
\hline 1 & $8.0344 \mathrm{E} 10$ & $-2.60278 \mathrm{E} 12$ & $2.68312 \mathrm{E} 12$ & 2.76 \\
\hline
\end{tabular}

The table of outliers lists all observations that have Studentized residues greater than 2, in absolute value. The Studentized residuals measure how many standard deviations each observed pbo value is defined from the fitted model, using all data except that observation. In this case, there is a Studentized residue greater than 2, but none greater than the influential points table lists all observations that have influence values greater than 3 times that of an average point in the data, or that have an unusual value of DFITS. Influence Value is a statistic that measures how influential each observation is in determining the coefficients of the estimated model. DFITS is a statistic that measures how much-estimated coefficients could change if observation were removed from the dataset. In this case, an average point in the data would have an influence value equal to 0.3 . There are no points with more than 3 times the average influence value. There are 2 data with unusually large DFITS values.

\subsection{Automatic forecasting model - PBO}

\section{AUTOMATIC FORECASTS - PBO}


Data/Variable: pbo

Number of observations $=11$

Initial Index $=1.0$

Sample Interval $=1.0$

Forecast Summary

Selected forecast model: ARIMA $(0,2,2)$

Number of forecasts generated: 5

Number of periods retained for validation: 0

\begin{tabular}{|l|l|}
\hline & Period of \\
\hline Statistical & estimate \\
\hline RMSE & $6.33272 \mathrm{E} 11$ \\
\hline dude & $4.72184 \mathrm{E} 11$ \\
\hline ASM & 9,02893 \\
\hline me & $1.68334 \mathrm{E} 11$ \\
\hline Mpe & 7,65961 \\
\hline
\end{tabular}

ARIMA Model Summary

\begin{tabular}{|l|l|l|l|l|}
\hline Parameter & Estimated & $\begin{array}{l}\text { Estimation } \\
\text { Error }\end{array}$ & $t$ & $P$-value \\
\hline MA(1) & -1.16199 & 0.27106 & $-4,28684$ & 0,003625 \\
\hline MA(2) & $-0,860467$ & 0,168472 & $-5,10749$ & 0,001388 \\
\hline
\end{tabular}

\section{Historical Forecast: yes}

Estimated white noise variance $=4.03345 \mathrm{E} 23$ with 7 degrees of freedom

Estimated standard deviation of white noise $=6.35094 \mathrm{E} 11$

\section{Number of iterations: 5}

This procedure predicts future pbo values. The data covers 11 time periods. Currently, the model of an integrated autoregressive moving average (ARIMA) has been selected. This model assumes that the best forecast available for future data is given by the parametric model that relates the most recent value to the previous values and noise.

The output summarizes the statistical significance of the terms in the forecasting model. Terms with P-values less than 0.05 are statistically nonzero with a confidence level of $95.0 \%$. The P-value for the term MA(2) is less than 0.05 , so it is statistically different from 0 . The estimated standard deviation of the input white noise is equal to $6.35094 \mathrm{E} 11$.

This table also summarizes the performance of the currently selected model in fitting historical data. It shows:

(1) the root of the mean square error (RMSE)

(2) the mean absolute error (MAE)

(3) the average absolute error rate (ASM)

(4) the mean error (ME)

(5) the average error rate (MPE)

Each of the statistics is based on the one-forward forecasting errors, which are the differences between the data at time $t$ and the predicted value at time $t-1$. The first three statistics measure the magnitude of errors. A better model would give a smaller value. The last two statistics measure bias. A better model would give a value closer to 0 . 
PBO AS A FUNCTION OF TIME CHART

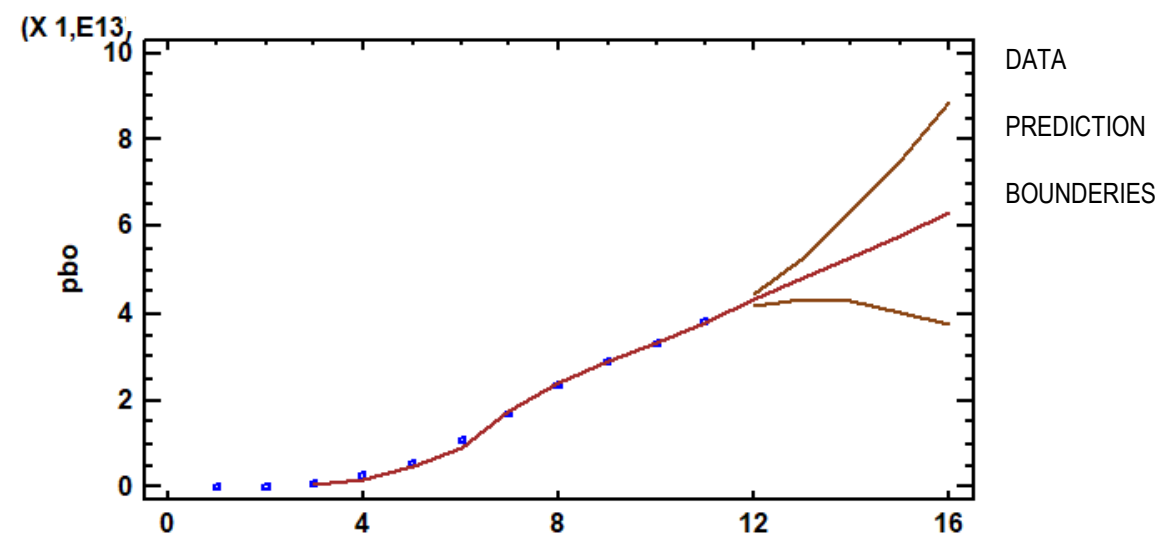

95,0

Forecast Table for pbo

Model: ARIMA $(\mathbf{0 , 2 , 2 )}$

\begin{tabular}{|l|l|l|l|}
\hline Period & Data & Forecast & Residual \\
\hline 1.0 & $8.0344 \mathrm{E} 10$ & & \\
\hline 2.0 & $2.92796 \mathrm{E} 11$ & & \\
\hline 3.0 & $9.60009 \mathrm{E} 11$ & $6.39546 \mathrm{E} 11$ & $3.20463 \mathrm{E} 11$ \\
\hline 4.0 & $2.5917 \mathrm{E} 12$ & $2.01939 \mathrm{E} 12$ & $5.72313 \mathrm{E} 11$ \\
\hline 5.0 & $5.56348 \mathrm{E} 12$ & $5.16416 \mathrm{E} 12$ & $3.99321 \mathrm{E} 11$ \\
\hline 6.0 & $1.07046 \mathrm{E} 13$ & $9.49173 \mathrm{E} 12$ & $1.21292 \mathrm{E} 12$ \\
\hline 7.0 & $1.71081 \mathrm{E} 13$ & $1.75988 \mathrm{E} 13$ & $-4.9073 \mathrm{E} 11$ \\
\hline 8.0 & $2.36195 \mathrm{E} 13$ & $2.3985 \mathrm{E} 13$ & $-3.6553 \mathrm{E} 11$ \\
\hline 9.0 & $2.88058 \mathrm{E} 13$ & $2.92838 \mathrm{E} 13$ & $-4.7799 \mathrm{E} 11$ \\
\hline 10.0 & $3.34996 \mathrm{E} 13$ & $3.31223 \mathrm{E} 13$ & $3.77314 \mathrm{E} 11$ \\
\hline 11.0 & $3.81874 \mathrm{E} 13$ & $3.82205 \mathrm{E} 13$ & $-3.30757 \mathrm{E} 10$ \\
\hline
\end{tabular}

\begin{tabular}{|l|l|l|l|}
\hline & & Limit at 95.0\% & Limit at 95.0\% \\
\hline Period & Forecast & Lower & Upper \\
\hline 12.0 & $4.31614 \mathrm{E} 13$ & $4.16597 \mathrm{E} 13$ & $4.46632 \mathrm{E} 13$ \\
\hline 13.0 & $4.8107 \mathrm{E} 13$ & $4.31266 \mathrm{E} 13$ & $5.30874 \mathrm{E} 13$ \\
\hline 14.0 & $5.30526 \mathrm{E} 13$ & $4.25139 \mathrm{E} 13$ & $6.35912 \mathrm{E} 13$ \\
\hline 15.0 & $5.79982 \mathrm{E} 13$ & $4.06132 \mathrm{E} 13$ & $7.53832 \mathrm{E} 13$ \\
\hline 16.0 & $6.29437 \mathrm{E} 13$ & $3.76547 \mathrm{E} 13$ & $8.82328 \mathrm{E} 13$ \\
\hline
\end{tabular}

This table shows the predicted values for pbo. During the period where data are available, the predicted values of the fitted model and the residuals (data-forecast) are also displayed. For time periods beyond the time series, the $95.0 \%$ prediction limits for forecasts are displayed. These limits show where the true value of the data might be, at the selected future time, with $95.0 \%$ confidence, assuming that the fitted model is appropriate for the data. 


\section{FORECAST CHART FOR PBO}

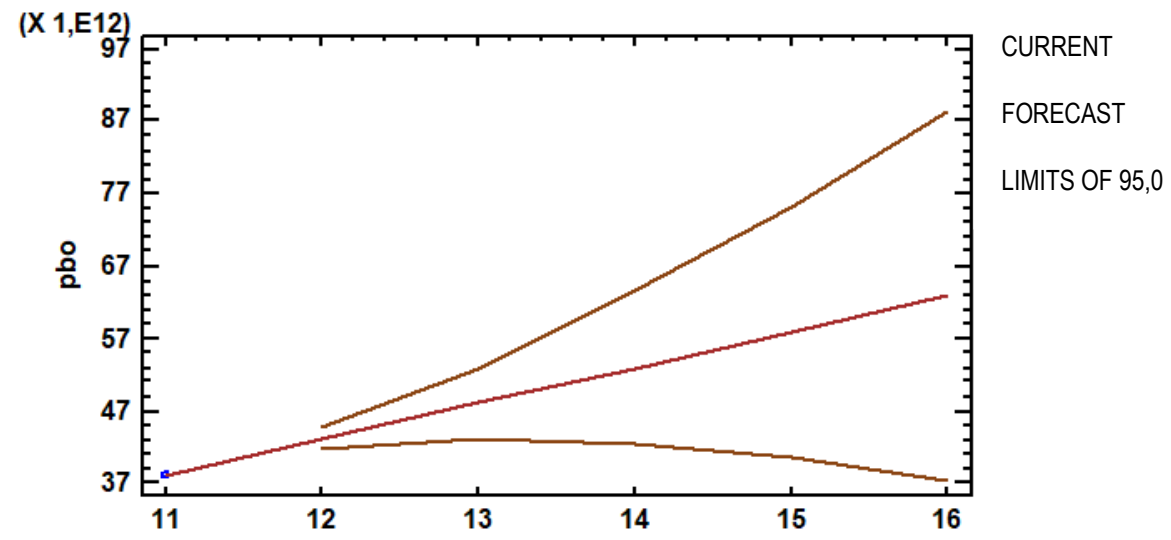

35,0

NORMAL PROBABILITY CHART FOR

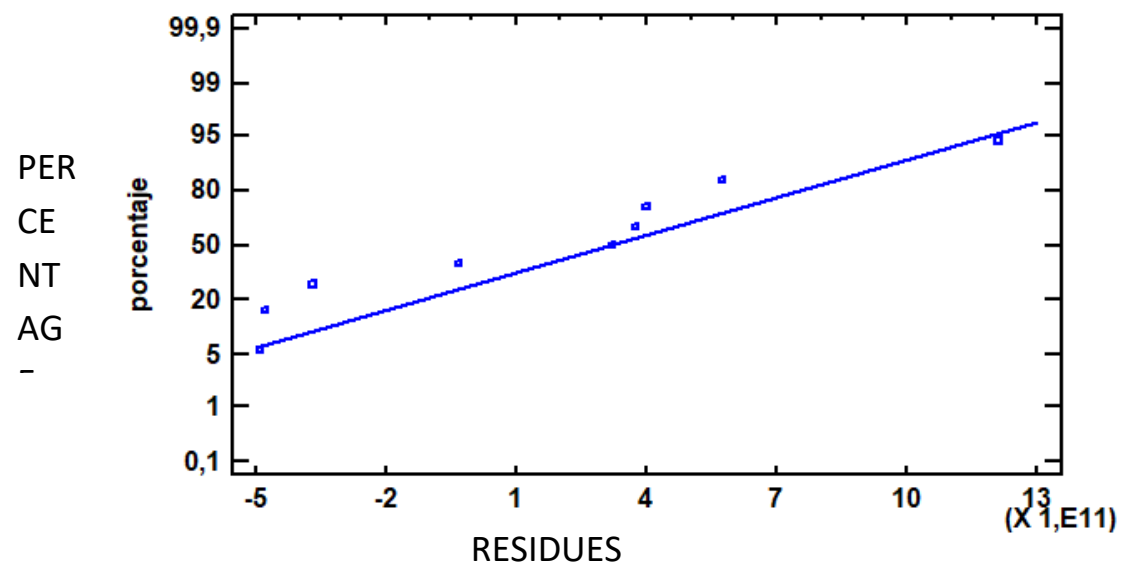

\section{ESTIMATED AUTOCORRELATIONS FOR ATYPICAL VALUES}

Data variable: pbo

Model: $\operatorname{ARIMA}(0,2,2)$

\begin{tabular}{|l|l|l|l|l|}
\hline & & & Limit at 95.0\% & Limit at 95.0\% \\
\hline Lag & Autocorrelation & $\begin{array}{l}\text { Error } \\
\text { Estimation }\end{array}$ & Lower & Upper \\
\hline 1 & 0,0890788 & 0,333333 & $-0,653323$ & 0,653323 \\
\hline 2 & 0,0751528 & 0,335968 & $-0,658486$ & 0,658486 \\
\hline 3 & $-0,366741$ & 0,337831 & $-0,662137$ & 0,662137 \\
\hline
\end{tabular}

This table shows the estimated autocorrelations between the residuals at different delays. The delaying autocorrelation coefficient $\mathrm{k}$ measures the correlation between residuals at time $\mathrm{t}$ and time $\mathrm{t}-\mathrm{k}$. Probability limits of $95.0 \%$ around 0 are also shown. If the probability limits to a particular delay do not contain the estimated coefficient, there is a statistically significant correlation to that delay to the $95.0 \%$ confidence level. In this case, none of the 24 autocorrelation coefficients is statistically significant, implying that the time series may well be completely random (white noise). 


\section{ESTIMATED SELF-CORRELATIONS FOR ATYPICAL VALUES}

Data variable: pbo

Model: ARIMA $(0,2,2)$

\begin{tabular}{|l|l|l|l|l|}
\hline & & & limit in 95,0\% & limit in 95,0\% \\
\hline Lag & Auto correlation & Error Estd. & lower & higher \\
\hline 1 & 0.0890788 & 0.333333 & -0.653323 & 0.653323 \\
\hline 2 & 0.0751528 & 0.335968 & -0.658486 & 0.658486 \\
\hline 3 & -0.366741 & 0.337831 & -0.662137 & 0.662137 \\
\hline
\end{tabular}

This table shows the estimated auto correlations between the residuals at different lags. The lagged auto correlation coefficient $\mathrm{k}$ measures the correlation between the residuals at time $\mathrm{t}$ and time $\mathrm{t}-\mathrm{k}$. $95.0 \%$ probability limits around 0 are also shown. If the probability limits at a particular delay do not contain the estimated coefficient, there is a statistically significant correlation to that delay at the $95.0 \%$ confidence level. In this case, none of the 24 auto correlation coefficients is statistically significant, implying that the time series may well be completely random (White noise).

\section{RESIDUALS AUTOCORRELATION CHART}

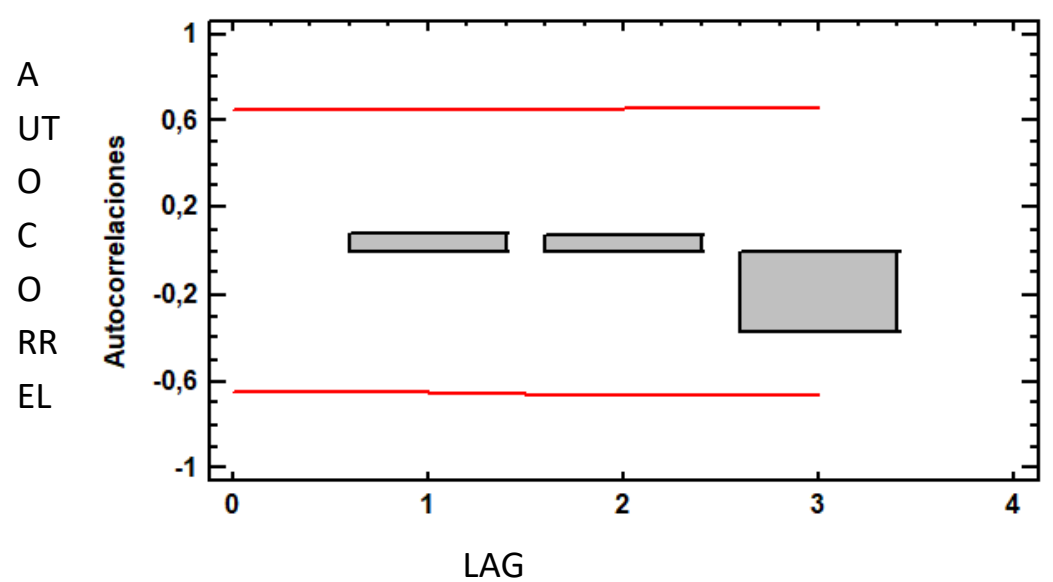

\section{Conclusions}

Based on the above analyses, it is apparent that both types of models are useful for making predictions of actuarial liability levels given by PBO Projected Benefit Obligations on and off the horizon of the sample time series. As we have seen in prior research, (Baker, 2003), (Godwin, et al. (1996) (Lin, 2000) and Wu, et al. (2013), the use of multivariate models for control and auditing purposes is widely recommended. Fast and reliable statistical estimates are desirable in all cases, whether for audit purposes or to verify and validate miscellaneous actuarial results.

The main contribution of the paper is that through both models reasonably good approximate results can be given, without the need to carry out recurrent actuarial assessments whose cost can be substantial, in the event that there is a need to make a significant number of them. In addition, the response time of regular actuarial valuations could be a little longer and consequently obtain extemporaneous results relatively close to those obtained in the valuations.

Within what might be called limitations, models would not consider an analysis of intervention of structural changes in benefits for obvious reasons. Obviously, new models could be adjusted in case this happens.

When negotiations on traded collective agreements are being discussed, this tool is of particular importance, because it is a process of strategic negotiation, timely and quality decision-making is invaluable. 
Both the multivariate regression and autoregressive modeling yield very reasonable estimates. This would undoubtedly allow for impact forecasts with changes in the interest rate. For example, at the level of multivariate regression.

However, when we analyze the ARIMA models, the estimates that the model throws outside the time horizon show the potential risks in the confidence bands of the predictions at $95 \%$ statistical confidence. This is of the utmost importance in order to administer a benefit plan and define risk control actions.

\section{Acknowledgements}

The authors thank all reviewers of this article for their insightful suggestions and comments. All the views expressed here and any errors are exclusively that of the authors.

\section{References}

[1]. Baker, T., Collins, D. \& Reitenga, A. (2003), Stock Option Compensation and Earnings Management Incentives, Journal of Accounting, Auditing \& Finance, 18(4), pp. 557-582. https://doi.org/10.1177/0148558X0301800408

[2]. Diz, E., \& Query, T. (2018). Using Multivariant Regression Analysis to Compute Longevity Risk and Actuarial Liability: The Case of Social Benefits for Workers in Venezuela. Journal of Finance and Economics - Special Issue on Longevity Risk. 6(2): 144-153. https://doi.org/10.12691/jfe-6-4-4

[3]. Godwin, J. H., Goldberg, S. R. and Duchac, J. E. (1996). An empirical analysis of factors associated with changes in pension-plan interest-rate assumptions. Journal of Accounting, Auditing and Finance 11: 2, 305323. https://doi.org/10.1177/0148558X9601100208

[4]. Hsu, A., Wu, C. and Lin, J. (2013). Factors in Managing Actuarial Assumptions for Pension Fair value: Implications for IAS 19. Review of Pacific Basin Financial Markets and Policies, 16: 1. https://doi.org/10.1142/S0219091513500021

[5]. Lin, S. W. C. J. L. (2000). Identifying Turning Points and Business Cycles in Taiwan: A Multivariate Dynamic Markov Switching Factor Model Approach. Academia Economic Papers, 28(3): 289-320. 


\section{APPENDICES}

\section{Appendix I}

Demographics

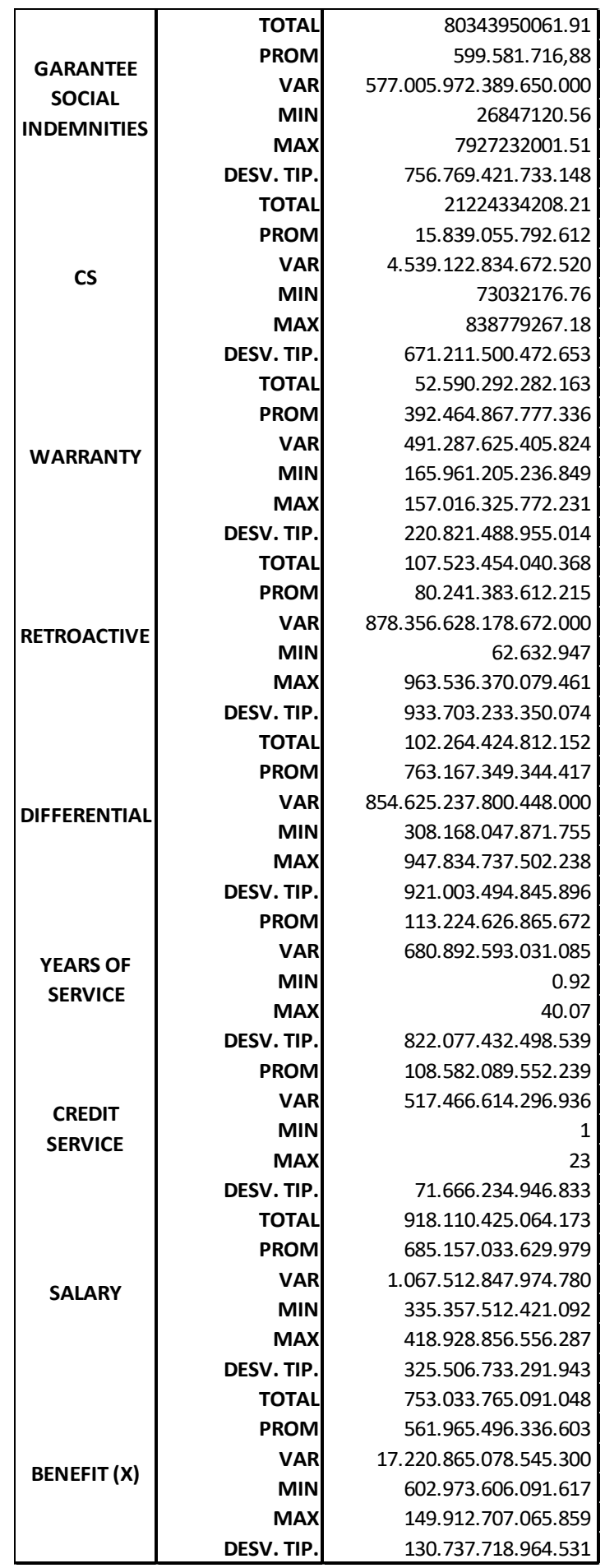


IRA-International Journal of Management \& Social Sciences

\section{APPENDIX II}

Actuarial Assumptions and Assumptions for 10 Years of Valuations

\begin{tabular}{|c|c|c|c|}
\hline YEARS & AVERAGE & ROTATION & $\begin{array}{c}\text { TOTAL } \\
\text { ROTATION }\end{array}$ \\
\hline 23 & 0.0003245 & 0.1699416 & 0.1702661 \\
\hline 24 & 0.000341 & 0.16122 & 0.161561 \\
\hline 25 & 0.0003585 & 0.152946 & 0.1533045 \\
\hline 26 & 0.000378 & 0.1450966 & 0.1454746 \\
\hline 27 & 0.000398 & 0.13765 & 0.138048 \\
\hline 28 & 0.0004215 & 0.1305856 & 0.1310071 \\
\hline 29 & 0.000446 & 0.1238838 & 0.1243298 \\
\hline 30 & 0.0004745 & 0.1175258 & 0.1180003 \\
\hline 31 & 0.0005045 & 0.1114942 & 0.1119987 \\
\hline 32 & 0.0005375 & 0.1057722 & 0.1063097 \\
\hline 33 & 0.000574 & 0.1003438 & 0.1009178 \\
\hline 34 & 0.000614 & 0.095194 & 0.095808 \\
\hline 35 & 0.000668 & 0.0903084 & 0.0909764 \\
\hline 36 & 0.0007045 & 0.0856738 & 0.0863783 \\
\hline 37 & 0.0007505 & 0.0812768 & 0.0820273 \\
\hline 38 & 0.000806 & 0.0771056 & 0.0779116 \\
\hline 39 & 0.0008725 & 0.0731484 & 0.0740209 \\
\hline 40 & 0.0009515 & 0.0693942 & 0.0703457 \\
\hline 41 & 0.001043 & 0.0658328 & 0.0668758 \\
\hline 42 & 0.001151 & 0.0624542 & 0.0636052 \\
\hline 43 & 0.001278 & 0.059249 & 0.060527 \\
\hline 44 & 0.0014255 & 0.0562082 & 0.0576337 \\
\hline 45 & 0.0015965 & 0.0533236 & 0.0549201 \\
\hline 46 & 0.001794 & 0.0505868 & 0.0523808 \\
\hline 47 & 0.0020135 & 0.0479906 & 0.0500041 \\
\hline 49 & 0.002509 & 0.0431912 & 0.0457002 \\
\hline 50 & 0.002778 & 0.0409746 & 0.0437526 \\
\hline 51 & 0.0030585 & 0.0388716 & 0.0419301 \\
\hline 52 & 0.0033515 & 0.0368768 & 0.0402283 \\
\hline 53 & 0.0036595 & 0.0349842 & 0.0386437 \\
\hline 54 & 0.0039875 & 0.0331888 & 0.0371763 \\
\hline 55 & 0.004336 & 0.0314854 & 0.0358214 \\
\hline 56 & 0.0047105 & 0.0298696 & 0.0345801 \\
\hline 57 & 0.005121 & 0.0283366 & 0.0334576 \\
\hline 59 & 0.0061025 & 0.0255026 & 0.0316051 \\
\hline 60 & 0.0066995 & 0.0241938 & 0.0308933 \\
\hline 62 & 0.0081715 & 0 & 0.0081715 \\
\hline 64 & 0.0101265 & 0 & 0.0101265 \\
\hline 65 & 0.011328 & 0 & 0.011328 \\
\hline 66 & 0.012698 & 0 & 0.012698 \\
\hline 70 & 0.0199575 & 0 & 0.0199575 \\
\hline
\end{tabular}

